\title{
To screen or not to screen: for high blood pressure
}

\author{
Kjell Tullus ${ }^{1}$
}

Received: 28 July 2017 / Accepted: 6 September 2017 /Published online: 2 October 2017

(C) IPNA 2017

We pediatric nephrologists regularly see children who benefit from diagnosis and treatment for their raised blood pressure (BP). Secondary organ manifestations, such as left ventricular hypertrophy, are seen to improve, and we believe that these children are likely to have a longer and healthier life because of our treatment.

At the same time, very few children in my hospital have their blood pressure measured routinely as part of their examination when they are seen by our colleagues outside of nephrology. This (my clinical feeling) is supported by several studies from the USA. Only one third of children attending a routine clinical visit had their blood pressure measured [1]. This was better for children coming for a preventive visit, but still only two thirds of these had their BP measured [1].

In one study, $71 \%$ of physicians only measured BP in children with risk factors for high BP, and $47 \%$ of the hypertensive or prehypertensive children were classified as normal [2]. Similarly, only 131 of 507 children with elevated BP (26\%) had this documented in their electronic medical records [3]. In another study of 1,143 children, $6 \%$ were shown to have a measured BP $>99$ th percentile $+5 \mathrm{mmHg}$ (thus showing marked hypertension), but still only $26 \%$ of these had high BP documented as a concern in their notes [4]. Another study showed that as many as $87 \%$ of children with elevated BP

Kjell Tullus

Kjell.Tullus@gosh.nhs.uk

1 Department of Paediatric Nephrology, Great Ormond Street Hospital for Children NHS Foundation Trust, Great Ormond Street, London, England WC1N 3JH, UK recordings did not have this recognized by their health provider [5].

A recent large study in 29,000 children found that only $64 \%$ had all normal BP readings [6]. Thirty-three per cent had one or two elevated BP measurements and $3 \%$ had three or more high readings. Still, in only $17 \%$ of the children with more than three high readings was high BP recognized.

Guidelines from Europe and the USA have strongly recommended regular BP screening. Lurbe et al., on behalf of the European Society of Hypertension, recommended that all children above 3 years of age should have their BP measured at every medical setting [7]. An expert panel from the USA recommended that all children above the age of three should have yearly BP measurements [8].

However, during the last decade, different kinds of screening programs have been thoroughly discussed and questioned regarding their potential benefit. It has been increasingly recognized that screening can have important beneficial health effects, but that it can also do significant harm. Breast cancer screening has, for example, become hotly debated. We now know that for every life saved from early detection of a breast cancer, there will be women who are unnecessarily treated for tumors that would never have caused them any harm [9]. Other unwanted side effects of screening are that it can lead to medicalization and can cause unnecessary worry.

This dual effect of BP screening in children has not, to my knowledge, been evaluated in any study. We strongly hope that screening does do good for the children, but we do not know to what extent it causes harm.

The debate on BP screening is thus very important and we have therefore invited two esteemed colleagues to present their views for and against BP screening $[10,11]$. 


\section{Compliance with ethical standards}

Conflicts of interest The author has no conflicts of interest to declare.

\section{References}

1. Shapiro DJ, Hersh AL, Cabana MD, Sutherland SM, Patel AI (2012) Hypertension screening during ambulatory pediatric visits in the United States, 2000-2009. Pediatrics 130:604-610

2. Bijlsma MW, Blufpand HN, Kaspers GJ, Bokenkamp A (2014) Why pediatricians fail to diagnose hypertension: a multicenter survey. J Pediatr 164:173-177

3. Hansen ML, Gunn PW, Kaelber DC (2007) Underdiagnosis of hypertension in children and adolescents. JAMA 298:874-879

4. Sleeper EJ, Ariza AJ, Binns HJ (2009) Do hospitalized pediatric patients have weight and blood pressure concerns identified? J Pediatr 154:213-217

5. Brady TM, Solomon BS, Neu AM, Siberry GK, Parekh RS (2010) Patient-, provider-, and clinic-level predictors of unrecognized elevated blood pressure in children. Pediatrics 125:e1286-e1293
6. Beacher DR, Chang SZ, Rosen JS, Lipkin GS, McCarville MM, Quadri-Sheriff M, Kwon S, Lane JC, Binns HJ, Ariza AJ (2015) Recognition of elevated blood pressure in an outpatient pediatric tertiary care setting. J Pediatr 166:1233-1239

7. Lurbe E, Cifkova R, Cruickshank JK, Dillon MJ, Ferreira I, Invitti C, Kuznetsova T, Laurent S, Mancia G, Morales-Olivas F, Rascher W, Redon J, Schaefer F, Seeman T, Stergiou G, Wühl E, Zanchetti A, European Society of Hypertension (2009) Management of high blood pressure in children and adolescents: recommendations of the European Society of Hypertension. J Hypertens 27:1719-1742

8. Expert Panel on Integrated Guidelines for Cardiovascular Health and Risk Reduction in Children and Adolescents, National Heart, Lung, and Blood Institute (2011) Expert panel on integrated guidelines for cardiovascular health and risk reduction in children and adolescents: summary report. Pediatrics 128 [Suppl 5]:S213-S256

9. No authors (2012) Breast cancer screening: one life saved at a cost of three overdiagnoses. BMJ 345:e7460

10. Litwin $M(2017)$ Why should we screen for arterial hypertension in children and adolescents? Pediatr Nephrol. https://doi.org/10.1007/ s00467-017-3739-8

11. Ide N, Thompson M (2017) Screening children for hypertension: the case against. Pediatr Nephrol. https://doi.org/10.1007\% 2Fs00467-017-xxxx-x 